\title{
LA EXTENSIÓN DEL CONVENIO ARBITRAL
}

\author{
Roberto Alejandro Palacios Bran*
}

Recibido: 26.09 .2014

Aprobado: 27.10.2014

\section{RESUMEN}

El convenio arbitral es un contrato, por lo que le son aplicables los principios de los contratos en general. La extensión del convenio a partes no signatarias parece trasgredir uno de estos principios que es el de res inter alios acta o del efecto relativo del contrato. Este principio establece que el contrato resulta obligatorio y produce efectos vinculantes entre las partes que lo celebraron, y excluye de dicho vínculo obligacional a los terceros o ajenos al negocio jurídico pactado. Por otra parte, existe la necesidad, dada la cada vez más compleja forma de contratación, de darle más eficacia al arbitraje como solución de controversias, a través de la extensión del convenio arbitral. Para esta extensión deberá exigirse un cuidadoso análisis de los hechos y de todas las circunstancias que rodean al caso, así como de las conductas desarrolladas por las partes involucradas que permita descubrir consentimientos implícitos por parte de los no signatarios. Es por todo esto, que el tratamiento más apropiado a la extensión debería tratarse como una excepción a los principios que rigen los contratos en general.

\section{ABSTRACT}

The arbitration agreement is a contract, so it applies the principles of contracts in general. The extension of the agreement to non-signatories seem to transgress one of these principles is that of res inter alios acta or relative effect of contract. This principle states that the contract is binding and produce binding effects between the parts that celebrated and excluded from that obligational to third parties or outside the agreed legal business link. Moreover, there is a need, given the increasingly complex form of recruitment, make it more effective to arbitration as dispute resolution, through the extension of the arbitration agreement. For this extension should be required careful analysis of the facts and all the circumstances surrounding the case and of the behaviors developed by the parties involved that allows discovering implicit consents from non-signatory. For all this, the most appropriate treatment for the extension should be treated as an exception to the principles governing contracts in general.

\section{PALABRAS CLAVE}

Arbitraje - Convenio arbitral - Contrato - Efecto relativo del contrato

\section{KEYWORDS}

Arbitration - Arbitration agreement - Contract - Privity of contract.

\section{SUMARIO}

1. Introducción. 2. El convenio arbitral como contrato. 2.1. Elementos del convenio arbitral. 2.2. Principios aplicables al convenio arbitral. 3. Extensión del convenio arbitral. 3.1. Nuestra legislación. 3.2. Criterios de extensión. 4. La problemática. 5. Conclusiones.

\footnotetext{
* Abogado y Magister en Derecho Civil Patrimonial, con estudios concluidos de Doctorado. Profesor Principal y Decano de la Facultad de Derecho de la Universidad César Vallejo. Ha sido Jefe de la SUNARP en Trujillo (2001-2006) y en Piura (2006-2007). Conciliador Extrajudicial, Arbitro integrante del panel de árbitros de la Cámara de Comercio de La Libertad. Profesor Principal y Decano de la Facultad de Derecho de la Universidad César Vallejo.
} 


\section{INTRODUCCIÓN}

Los principios no son absolutos. Una clara muestra de lo que afirmamos es lo que vemos que pasa en el derecho arbitral, en donde uno o más de los principios que informan el perfeccionamiento de los contratos en general parecen dejarse de lado para considerar una mejora mucho más efectiva en la resolución de los conflictos.

Empezaremos esta disertación mencionando la naturaleza contractual del convenio arbitral y los principios que le son aplicables a los contratos en general en relación al convenio arbitral; posteriormente, veremos cómo es que la realidad del comercio ha impulsado la inclusión en el ordenamiento jurídico nacional de la extensión del convenio arbitral a partes no signatarias. Una vez desarrollado esto, nos detendremos en la normatividad y a analizarla en sus supuestos, para finalmente saber si cada uno de éstos justifica la exclusión de alguno de los principios más importantes de los contratos en general, como es el principio res inter alios acta o el efecto relativo de los contratos.

\section{El CONVENIO ARBITRAL COMO CONTRATO}

El convenio arbitral consiste en «el acuerdo de las partes de someter a arbitraje toda controversia o cualquier controversia de derecho disponible que surja o pueda surgir entre ellas, derivadas de una determinada relación jurídica contractual o de otra naturaleza se denomina convenio arbitral» (Franciskovic, 2005; Santistevan, 2009: 28), «un acuerdo de voluntades dirigido a crear una relación jurídica de naturaleza patrimonial» (Bullard, s/f).

Los cambios producidos en la actual legislación, comparada con la anterior ley del arbitraje, se encuentran en «la naturaleza del convenio arbitral y las formalidades exigidas para su perfeccionamiento. Mientras que el modelo anterior se sustentaba en un convenio arbitral ad solemnitatem con predominancia de la forma escrita, la nueva ley se basa en un convenio arbitral ad probationem lo que en efecto trae consigo una mayor flexibilidad $\mathrm{y}$ «la posibilidad inclusive de un convenio verbal siempre que quede registro de ello para su comprobación posterior» (Santistevan, 2009: 19).

Para Santistevan (2009), la nueva ley adopta la naturaleza ad probationem del convenio arbitral porque «contribuye mejor a la eficacia del arbitraje» lo que encuentra una vinculación directa con la extensión del convenio arbitral. Esta nueva regulación «refleja la intención que toda interpretación del convenio arbitral se haga de manera extensiva, esto es favoreciendo la arbitrabilidad de las controversias» (Bullard, s/f).

Ruska Maguiña (2007, citado por Castillo Ugaz, 2014) señala que «el arbitraje se sustenta en la autonomía privada y su partida de nacimiento es el convenio arbitral, que no es otra cosa que un contrato» y Galluccio Tonder y Mori Bregante (2009, citado por Castillo Ugaz, 2014) afirma que «el origen del arbitraje es siempre un contrato, el Convenio Arbitral, y por ello la extensión del mismo únicamen- te puede hacerse en términos contractuales».

Como se puede apreciar, la definición de convenio arbitral se enmarca en un solo camino, que es la exteriorización de una voluntad reflejada en un acuerdo entre las partes; es decir, un contrato mediante el cual éstas buscan establecer como regla el sometimiento al arbitraje en relación a los problemas o posibles problemas de orden patrimonial que existan o puedan existir entre ellas, donde independientes -los árbitros- resolverán la materia de conflicto, quedando las partes sujetas al cumplimiento de dicha solución

Según Roque J. Caivano, «el contrato se encuentra sujeto por lo tanto a los requisitos generales establecidos por la legislación civil para la validez de los contratos: debe existir un consentimiento no viciado y expresado válidamente, prestado por personas capaces, que verse sobre un objeto lícito, posible y que se halle revestido de la forma legalmente escrita, si la hubiere»

Es así que la forma, modo o manera como se expresa o manifiesta la voluntad común de las partes de someter su controversia de derecho disponible al arbitraje es mediante la celebración de un convenio arbitral (Franciskovic, 2013).

\subsection{Elementos del convenio arbitral}

\section{A. Acuerdo de voluntades}

«El convenio arbitral debe manifestar la voluntad recíproca y concordante de las partes de someter al arbitraje las diferencias 
surgidas o que puedan surgir de cierta relación jurídica, expresando entonces la voluntad de renunciar a la justicia ordinaria y de acatar la decisión del tribunal arbitral que les es vinculante» (Follonier-Ayala, 2013: 134). «El consentimiento de las partes es por ende la fuente del arbitraje, y hace del convenio arbitral la piedra angular del procedimiento arbitral» (Follonier-Ayala, 2013: 135).

«Dicho consentimiento voluntario se ve plasmado en la suscripción de un convenio arbitral, el mismo que, como regla general, sólo puede ser oponible entre las partes firmantes del mismo, pues son ellas -y sólo ellas- quienes dieron su conformidad con tal pacto arbitral».

Al respecto, Trazegnies (2004) nos dice que:

«Por su origen y por su naturaleza, el convenio arbitral es un contrato. En consecuencia, como tal, es ley entre las partes, pero sus reglas no pueden ser aplicadas a terceros no signatarios. (...) Es en ese sentido que el artículo 1363 del Código Civil prescribe que los contratos sólo producen efectos entre las partes que los otorgan $y$ sus herederos. En consecuencia, en tanto que contrato que se rige fundamentalmente por la doctrina de la autonomía de la voluntad, el convenio arbitral debe ser respetado e interpretado en sentido restrictivo, no permitiendo que se extienda a quienes no han manifestado su voluntad de arbitrar, sea por suscripción o por adhesión (arbitraje estatutario)».

Pero, por otro lado, hemos de tener en cuenta que los contratos son susceptibles de interpretación en caso de que su decisión o contenido no sea muy claro y del cual no pueda inferirse la voluntad indubitable de alguna de las partes. El convenio arbitral es un contrato, por lo tanto, es a la vez interpretable. «Numerosos puntos ambiguos, contradictorios, oscuros o imprecisos pueden introducirse en el convenio arbitral, haciendo indispensable la determinación del sentido que las partes daban a sus manifestaciones recíprocas de voluntad. Típicamente, es el caso de los llamados convenios "patológicos" de arbitraje» (Follonier-Ayala, 2013: 126).

A este respecto, Follonier-Ayala (2013: 126-127) menciona:

«La interpretación de un convenio arbitral obedece a las reglas generales de la interpretación de las manifestaciones privadas de voluntad. Primeramente, el intérprete debe esforzarse por determinar, de hecho, la común y real intención de las partes (acuerdo de hecho). Si esta voluntad no puede ser establecida, el intérprete debe entonces buscar la voluntad presumida de las partes. Él tendrá que interpretar las declaraciones y los comportamientos de las partes según la teoría de la confianza, corolario del principio de la buena fe (acuerdo de derecho). Sin embargo, teniendo en cuenta las especificidades del arbitraje -elevados costos y vías de derecho limitadas- y la renunciación al fuero $y$ al juez natural que el convenio arbitral implica, su interpretación debe hacerse en conformidad con el principio exceptio est strictissimae interpretationis. Por consiguiente, el convenio arbitral se interpretará, en principio, de manera restrictiva. No obstante el reconocimiento universal de este principio de interpretación, la doctrina más sobresaliente estima que la interpretación restrictiva del convenio arbitral es contraria al principio in favor arbitrandum -concretización del principio general de interpretación in favor negotii- en virtud del cual y en la medida de lo posible, la validez de los convenios debe ser garantizada. Con todo, no sabríamos deducir de esto una presunción a favor del arbitraje».

El mismo autor expresa que, con la intención de conciliar estos dos principios antagonistas, la doctrina arbitral considera que se debe aplicar el principio de la interpretación restrictiva cuando la existencia misma del convenio arbitral es puesta en duda, mientras que el principio de la interpretación in favor arbitrandum se aplica cuando la existencia del 
convenio arbitral no es más puesta en tela de juicio.

Esto es considerar al arbitraje desde el punto de vista interpretativo como algo deseable por quienes se ven involucrados en el proceso, y que se verán beneficiados por las ventajas que ofrece el arbitraje en su holística dimensión, una reconsideración si el convenio arbitral se muestra al interprete o a las partes de que se preferirá evitar la judicialización del problema.

Pero ¿qué podemos entender como «no signatarias»?, esta noción «cobija a todas las personas que no están cubiertas formalmente por el convenio arbitral, pero que materialmente hablando están cubiertas por él, adquiriendo de este modo la calidad de partes del juicio arbitral. No se trata entonces de un tercero cualquiera, sino de un tercero calificado que por diversas razones gravita alrededor del convenio arbitral que lo vincula» (Follonier-Ayala, 2013: 148-149).

\section{B. Determinación de las partes}

Como todo contrato, el convenio arbitral debe ser concluido entre dos o más partes determinadas o determinables. Este elemento cobra una preponderancia particular en caso de contrato plurilateral o en caso de extensión del convenio arbitral a una parte no signataria. Puede tratarse de personas privadas o jurídicas, incluso de Estados o entidades públicas. Además, las partes deben gozar de la capacidad de contratar o estar válidamente representadas. Esta condición es habitualmente llamada arbitrabilidad subjetiva. «Las partes -determinadas o determinables- deben gozar, en materia de derecho de las personas, de la capacidad civil pasiva y activa y, en materia procesal, disponer de la capacidad de comprometerse y de participar en el proceso (Follonier-Ayala, 2013: 139).

\section{Determinación del objeto de la controversia}

El objeto de la controversia debe ser determinado o, por lo menos, determinable y, en todos los casos, ser arbitrable. El litigio puede derivarse de una relación jurídica de naturaleza contractual $o$ extracontractual y/o estar relacionado con ella (Follonier-Ayala, 2013: 158).

\subsection{Principios aplicables al convenio arbitral}

Bullard (s/f), haciendo una analogía del proceso arbitral como una fiesta -una fiesta bastante particular por cierto- siendo la invitación para la misma el convenio arbitral, menciona que hay varios principios fundamentales que determinan quién puede y quién no puede ser forzado a ir a la fiesta y a quien se va a dejar entrar a la misma. Estos principios son:

1. Las partes de un convenio no pueden desobligarse 0 desvincularse de ir a arbitraje si así lo consintieron. En consecuencia, los invitados que aceptaron asistir, ya no pueden dejar de hacerlo si la fiesta está convocada.
Este principio, que no es otro que el de obligatoriedad de los contratos (pacta sunt servanda), está protegido por principios como el de inevitabilidad del arbitraje, separabilidad del convenio y el kompetenz-kompetenz, que se orientan a limitar la creación de obstáculos que impidan que se arbitre.

2. Un tercero al convenio arbitral no puede ser incorporado a la fiesta, si es que no ha aceptado participar en ella. El tercero podrá entonces oponerse al arbitraje planteando excepciones 0 defensas previas o incluso de fondo, por las que sostendrá que los árbitros no son competentes para juzgarlo al no ser parte del convenio.

3. Un tercero no puede meterse a la fiesta sin el consentimiento de quienes ya están en ella. En ese caso, serán quienes ya están incorporados en el arbitraje, los que tendrán que oponerse a la incorporación del tercero, sosteniendo que están contractualmente facultados a rechazar su participación. En ese sentido, defenderán la idea de la privacidad del arbitraje, es decir, de que el contrato convoca a las partes y solamente a las partes, y reforzarán su negativa con la idea de confidencialidad de las actuaciones arbitrales.

\section{Extensión del Convenio AR- BITRAL}

¿Bajo qué contexto socioeconómico es que se realiza esta innovación legislativa en nuestro país? Es necesario responder brevemente a esta pregun- 
ta para poder ubicarnos en el tiempo, las formas del comercio y las decisiones adoptadas por instancias internacionales conforme a ellas. La innovación legislativa no lo es jurisprudencialmente, pues en instancias internacionales los casos de extensión han sido materia de debate en razón a las decisiones de incluir en el proceso arbitral a partes no signatarias, cuyo consentimiento para ser incluido como elemento subjetivo en el convenio arbitral no pudo ser inferido sino a través de la conducta exteriorizada que exhibían las partes en determinados estadios del contrato.

Pues hablamos de una adopción de vanguardia, dado que «los esquemas actuales son el resultado de operaciones transnacionales complejas, estructuradas sobre la base de una multiplicidad de partes y de contratos que constituyen una sola transacción económica y que derivan en procedimientos arbitrales igual de complejos (Conejero e Irra, 2013: 58), «se dan en la contratación actual, además, verdaderos multicontratos, o contratos eslabonados o constelación de contratos en los que la cláusula arbitral puede estar incursa en el contrato marco o contrato madre o contrato nuclear al que se remiten otros que no la contienen, por lo que tendría que admitirse su extensión por derivación o referencia». A la vez, "se presenta también la figura de los contratos y la subcontratación que depende del contrato principal y que pueden guardar silencio en relación al arbitraje pactado en el contrato principal». Esto último vinculado estrechamente con las contrataciones estatales en los que se derivan posterior- mente con respecto al cumplimiento de determinados aspectos del contrato a terceros subcontratistas para su ejecución. «El comercio internacional, la globalización, la estructuración de las inversiones y la propia división del trabajo entre distintos agentes para el cumplimiento de un contrato principal pueden brindar la posibilidad de romper la coincidencia entre los signatarios del convenio arbitral y otros que siendo partes en la ejecución no lo han suscrito» (Santistevan, 2009: 24).

\subsection{Nuestra legislación}

Veamos en primer lugar qué establece expresamente el artículo 14 del Decreto Legislativo 1071:

«Artículo 14.- Extensión del convenio arbitral.

El convenio arbitral se extiende a aquellos cuyo consentimiento de someterse a arbitraje, según la buena fe, se determina por su participación activa y de manera determinante en la negociación, celebración, ejecución o terminación del contrato que comprende el convenio arbitral o al que el convenio esté relacionado. Se extiende también a quienes pretendan derivar derechos o beneficios del contrato según sus términos».

Lo que doctrinaria y jurisprudencialmente ha llevado a configurar legalmente este artículo no ha sido ni seguirá siendo una aceptación pacífica, teniendo en cuenta que al convenio arbitral se le aplican los atributos propios del contrato que están contenidos en el artículo 1361 del Código Civil, el que estable- ce que: i) los contratos son obligatorios en cuanto se haya expresado en ellos; y ii) en la medida en que le es relevante al convenio arbitral la presunción del citado artículo en el sentido de que la declaración expresada en el contrato responde a la voluntad común de las partes (Santistevan, 2009: 28).

Si hemos de tener al convenio arbitral como contrato, le han de ser aplicables los tres principios esenciales de la contratación, a saber: 1) pacta sunt servanda, 2) lex inter partes y 3) res inter alios acta.

El primero tiene relación con la autonomía de la voluntad que se configura como el elemento esencial sobre el que reposa el contrato: el acuerdo de voluntades. En el caso del convenio arbitral: el consentimiento de someter las controversias a arbitraje renunciando a la jurisdicción en manos del Poder Judicial.

Como consecuencia de lo anterior, lo pactado (que en principio recoge el consentimiento de las partes) se convierte en ley entre ellas que debe ser rigurosamente respetada (lex inter-partes)

El tercer principio (res inter alios acta), consiste en que el contrato solamente resulta obligatorio y produce efectos vinculantes entre las partes que lo celebraron (y sus herederos), lo que excluye de dicho vínculo obligacional a los terceros 0 ajenos al negocio jurídico pactado. Así lo consagra el artículo 1363 del Código Civil que señala que «los contratos sólo producen efectos entre las partes que los otorgan y sus herederos». 
Este principio, en su sentido negativo, consiste en la «imposibilidad de que un tercero exija a una de las partes del contrato el cumplimiento de la prestación pactada frente a la otra parte, ya que no media entre ellos relación contractual alguna». La que en su contenido moral versaría en que «nadie puede ser obligado a responder por aquello a lo que no se obligó» (Amat, 2003: 1281).

En términos del derecho civil, esto se conoce como el efecto relativo del contrato, que obliga a admitir que el impacto directo del contrato recae exclusivamente sobre las partes, que como consecuencia de ello adquieren un status determinado de acreedor y deudor de los derechos u obligaciones contractuales. En nuestro caso del convenio arbitral, esta consecuencia directa que garantiza el involucramiento de las partes en el arbitraje coincide con el efecto positivo del convenio arbitral que se traduce en el derecho que tiene cada una de las partes de exigir que las controversias se sometan a arbitraje.

Mientras tanto, los efectos indirectos o reflejos suponen que los terceros o ajenos deben reconocer y respetar el efecto que generó el contrato entre quienes voluntariamente lo celebraron y el status que adquirieron por el efecto directo quienes lo suscribieron. Los efectos indirectos o reflejos del contrato se asemejan al efecto negativo del convenio arbitral que supone el veto a la intervención de los jueces y tribunales del Poder Judicial, en relación a las controversias arbitrables.
De La Puente y Lavalle, en relación a esto, manifiesta que «el contrato es un acto de ejercicio de un poder de autonomía privada y la autonomía privada consiste en la posibilidad de dictar la ley -el precepto- por el cual se ha de regir la propia esfera jurídica. Un contrato con una eficacia en la esfera jurídica de terceras personas, no sería un acto de autonomía, sino que constituiría una invasión de la esfera jurídica ajena».

Merino Merchán y Chillón Medina (2006, citados por Santistevan, 2009) en materia arbitral sobre el convenio arbitral establecen que «vincula a las partes pero solo a ellas. El principio de res inter alios acta brilla aquí en todo su esplendor. En consecuencia, no puede plantearse un proceso arbitral respecto de quienes no han sido parte en la convención de arbitraje».

De esta manera, nuestro principio en mención no puede dejar de ser tomado en cuenta bajo el contexto de las modernas modalidades de negociación y del comercio internacional, que constituyen un obstáculo en muchos casos insuperable, para resolver todas las dificultades inherentes a la resolución de un litigio, máxime en el plano del arbitraje internacional en el que es más frecuente la presencia de partes con distintos cometidos dentro del contrato principal y la presencia asimismo de consorcios sometidos a diversos ordenamientos cada uno de ellos; todo ello enmarcado por la magnitud y complejidad de los contratos base o principales (Merino Merchán y Chillón Medina, 2006).
Además, la teoría de la relatividad del contrato, «que usualmente es justa y eficiente en diversos contextos contractuales, resulta a veces contraria a las exigencias de justicia», y al «fundamento moral de la teoría puede oponerse otro principio que tiene el mismo carácter: no es equitativo que una persona deje de responder frente a terceros escudándose en el hecho de que no es parte en el contrato». La doctrina anglosajona en este respecto considera una «exigencia de equidad» (Amat, 2003: 1285-6).

A todo esto, surge la necesidad de establecer cómo y cuándo, y en qué particulares circunstancias y sobre todo bajo qué criterios puede hacerse extensivo el convenio arbitral a quienes no se mostraron como celebrantes, pero que están vinculados estrechamente a la negociación que motivó el surgimiento de un pacto arbitral y, «por necesidad de eficacia de esta modalidad de solución de controversias, resultan estar en una posición equivalente a la de las partes y merecen ser atraídas al convenio arbitral -y al arbitraje mismo eventualmente- para resolver las controversias que se derivan de dichos contratos» (Santistevan, 2009: 32).

Veamos algunos de los criterios.

\subsection{Criterios de la extensión}

Debido a la variedad de criterios utilizados en la extensión de la cláusula compromisoria a partes no signatarias, y a la poca uniformidad que existe en las distintas jurisdicciones sobre los criterios aceptados, hemos seleccionado los que, producto de la revisión de múl- 
tiples fuentes, consideramos más comúnmente aceptados y que por lo tanto han sido más desarrollados a nivel doctrinario y jurisprudencial (Villalobos y Paris 2013: 24).

Una de las tesis que han sido adoptadas es que deberá extenderse los efectos de la cláusula cuando el tercero haya participado del proceso de ejecución del contrato por el cual se pacta la cláusula compromisoria y, por lo tanto, presenta una vinculación directa con el mismo. En este sentido, podemos citar la decisión de la Corte de Apelaciones de París del 15 de Junio de 1989 que sobre un caso similar determinó:

«La cláusula arbitral de un contrato internacional tiene validez y eficacia por sí misma, que debe ser interpretada extendiendo sus efectos a partes directamente involucradas en la ejecución contractual, y en las disputas que puedan derivarse de ella, una vez que se haya establecido que su posición contractual y su conducta demuestran que han aceptado el acuerdo arbitral su existencia y su alcance, a pesar de que no lo hayan firmado" (Las cursivas son nuestras).

Esta situación podría darse en varios supuestos, siendo el más común el caso de grupos de sociedades en dónde por alguna razón la parte signataria del contrato delega parte de la ejecución del mismo en alguna de las empresas del grupo y ésta, con la ejecución del contrato que realiza, acepta tácitamente el contrato, la cláusula arbitral y sus alcances.
En la jurisprudencia norteamericana, el antecedente más importante se dio en el caso Thomson - CFC, S.A.C. American Arbitration Association, en el que, según Santistevan (2009: 37-40) citando a Thomson (2006), se delineó las teorías bajo las cuales las partes no signatarias resultarían comprometidas en el marco de un acuerdo de un convenio arbitral bajo el common law. Estas teorías consisten en las siguientes:

\section{Incorporación por referen-} cia: Cuando un contrato que no contiene cláusula arbitral se refiere a otro contrato que sí lo tiene. Se trata de contratos interrelacionados en los que se hace referencia expresa y directa a otro contrato que contiene una cláusula arbitral, como ocurre típicamente en los conocimientos de embarque, los contratos encadenados de construcción e ingeniería y los contratos de garantía.

2. Asunción de obligaciones (assumption): Situación entre el firmante y el no firmante en la que existe una relación de representación o agencia.

3. Rasgamiento del velo societario (veil piercing/alter ego): Se aplica a las relaciones entre matriz y subsidiaria cuando esta es lo suficientemente evidente como para que justifique el descorrimiento del velo societario para hacer a la principal responsable de la acción de sus empresas dependientes y convocarla a arbitraje. Tiene relación con lo que ha desarrollado la doctrina francesa sobre el grupo de sociedades.
4. Estoppel/equitable estoppel: Cuando una de las partes, por su propia conducta en relación al contrato, está impedida de negarle a la otra su acceso a la opción arbitral. Así, se ha obligado a las partes no signatarias que con plena conciencia reciben beneficios del contrato principal a someterse a la cláusula arbitral que no firmaron, dándole la oportunidad al firmante de llevar a la otra parte a arbitraje.

\section{Cesión de posición contrac-} tual (assignment): Como resultado de la cesión de posición contractual, quienes se incorporan al contrato se ven sometidos al arbitraje aunque no hayan suscrito el convenio arbitral original, con la particularidad que dichas Cortes suelen analizar de cerca tanto el convenio original como la cesión de posición contractual para verificar si el resultado es consistente con la intención de las partes.

\section{Estipulación en beneficio de} tercero / Third party beneficiary: Esta figura supone que, bajo ciertas circunstancias, una parte signataria que haya recibido beneficios del contrato subyacente tiene el derecho a demandar el cumplimiento de dichos beneficios. Ello supondría que la parte beneficiaria debería también someterse a arbitraje cuando es demandante en relación con prestaciones derivadas del contrato que lo benefició (Hosking).

7. Grupo de sociedades: Aplicada en algunos casos cuando se busca la aplicación del 
convenio arbitral a una compañía madre, de parte de otros miembros del grupo de sociedades o de los firmantes de un acuerdo de accionistas o de sus ejecutivos o directores.

\section{LA PROBLEMÁTICA}

Las dificultades a simple vista en la aplicación de este artículo versarían sobre la interpretación que puede dársele en los casos en concreto, y no hablamos de solucionar recurriendo simplemente a la doctrina y a la jurisprudencia arbitral internacional, sino a los criterios en específico a emplearse, que deberán compartir -porque lo predecible de una decisión es fundamentallos árbitros para considerar a tal actividad, conducta o comportamiento perteneciente a la clase conceptual de "participación activa» suficientemente «determinante en la negociación, celebración, ejecución o terminación del contrato». La suficiencia en esta participación activa sólo podrá ser particularizada en los casos en concreto donde pueda «intuírsela» en un primer momento, para después, en base a las pruebas ofrecidas «suficientemente», para poder acreditar o generar por lo menos fundadas sospechas de que el convenio arbitral puede ser extendido a las partes no signatarias ofrecidas para su inclusión por la parte interesada.
En palabras de Talero Rueda (2011):

«En el caso de la extensión de un pacto arbitral a no signatarios, la interpretación busca determinar los sujetos que se encuentran cobijados por aquél. Esta interpretación, por lo general, obedece al vacío o silencio del pacto arbitral respecto de sus alcances $r a-$ tione personae. En efecto, los pactos arbitrales, con frecuencia, se insertan en cláusulas arbitrales contenidas en contratos suscritos por partes claramente determinadas e identificadas. Dichas partes, por razones prácticas y de lógica comercial, no suelen analizar ni regular la posibilidad de que sus compromisos vinculen $\mathrm{u}$ obliguen directamente a quienes no han cerrado formalmente el respectivo negocio».

La jurisprudencia en nuestro país, por su parte, emplea los criterios desarrollados por la jurisprudencia francesa y los avances de la jurisprudencia norteamericana ${ }^{1}$, pero en medio de la esperada contradicción, por quienes en palabras de Bullard son invitados por la fuerza a ser parte de la fiesta, se observa una manifiesta resistencia a aceptar que los principios que rigen la libre contratación en el país, y sobre todo en materia civil, se vean dejados de lado por una innovación legislativa.

Hemos de notar que «si no existe uniformidad de criterio en cuanto a la posibilidad de extender la cláusula arbitral a terceros, tampoco en aquellas jurisdicciones donde se ha aceptado dicha extensión existen criterios uniformes en cuanto a los supuestos donde tal extensión debe aplicarse» (Villalobos y Paris, 2013: 7), en donde «lo relevante es ver si de la conducta desarrollada por la parte se puede presumir que existió, o debía derivarse en buena fe, la voluntad de arbitrar, así en el momento en que surja el conflicto ya no se quiera ir a arbitraje» (Bullard, $s / f)$.

\section{Conclusiones}

Es por todo esto, que el tratamiento más apropiado a la extensión debería tratarse como una excepción a los principios que rigen los contratos en general, ${ }^{2}$ y especialmente al convenio arbitral, y en su ofrecimiento así como en la aceptación de incluir a partes no signatarias en el proceso deberá hacerse detalladamente en el ofrecimiento de los medios probatorios y de manera muy rigurosa, por otra parte, en su aceptación, interpretando de manera restringida el supuesto de «participación activa» a lo que realmente pueda resultar determinante en la negociación, celebración, ejecución o terminación del con-

1 Exp. 451-2009 Corte Superior de Justicia de Lima, en anulación de laudo, considerando séptimo: «Ello dado que la consecuencia de levantar el velo societario implica desconocer la responsabilidad limitada de cada sociedad y por el contrario obliga que todas las sociedades del grupo respondan ilimitadamente por las deudas de una de ellas puesto que se entiende que han actuado bajo una voluntad común».

2 Exp. 451-2009 Corte Superior de Justicia de Lima, considerando octavo: «La afirmación [del demandado]. Como lo muestra la ley, la doctrina y la jurisprudencia, existen supuestos -excepcionales pero no por ellos menos reales- en los que los efectos de un convenio arbitral se pueden extender válidamente frente a personas que no lo suscribieron». 
trato, y no cualquier tipo de «participación activa» a la que no pueda atribuírsele causalidad sobre los efectos que se objetivizan en función al contrato ${ }^{3}$.

Tal como lo menciona Roldan Martínez (2012), «la misma exige cierto grado de prueba y justificación jurídica puesto que, básicamente, se centra en supuestos en los que se quiebran principios esenciales del ordenamiento jurídico poniéndolos en relación el de buena fe, de forma que el contrapunto entre las soluciones a adoptar y los perjuicios que se pretenden evitar tienen que ser analizados teniendo en cuenta un estadio posterior, como es el reconocimiento y ejecución del laudo».

$\mathrm{Si}$ bien es cierto, teniendo en claro que la materia aún es poco profusa en lo que distinguimos en la jurisprudencia nacional, uno de los problemas de la extensión del convenio arbitral es, como ya lo mencionó Rodal Martínez (2012), el del reconocimiento y ejecución del laudo, «por cuanto las decisiones adoptadas en el mismo pueden suponer la quiebra de principios básicos del ordenamiento jurídico del Estado donde se pretende conseguir la efectividad de la resolución arbitral, y pueden generar las acciones de anula- ción que desvirtúen el fallo del mismo por falta de cumplimiento de otros principios esenciales del derecho como puede ser el derecho de defensa». ${ }^{4}$

De esta manera, los elementos probatorios deberán ser concurrentes y graves que puedan conferir peso a las afirmaciones contenidas en la solicitud de traer nuevos invitados, y si estos elementos de prueba no resultaren del todo pero sí lo suficientemente capaces de infundir sospechas, el tribunal arbitral, en base a sus facultades conferidas por el artículo 43 de la ley arbitral, podrá ordenar la presentación o la actuación de las pruebas que estimara necesarios para satisfacer la condición de la «participación activa» determinante, pero no podrá en ningún momento, de manera lesiva, fundar su decisión en dichos, corazonadas o en la mera intuición producto de una deficiente probanza.

Para terminar, es importante subrayar el beneficio que puede alcanzar esta adopción moderna de la extensión del convenio arbitral que son las razones de eficiencia, «en cuanto a que conducir un único arbitraje por o en contra partes signatarias y no signatarias debería ofrecer mayores condiciones de celeridad y menores costos y, por úl- timo, se evidencien decisiones contradictorias o incompatibles que puedan resultar de dos o más procedimientos paralelos que versan sobre una misma cuestión controvertida» (Conejero e Irra, 2008: 59).

Pero, nuevamente, como ya lo dijimos, con la necesidad de darle eficacia al arbitraje como solución de controversias, la extensión del convenio arbitral exige un cuidadoso análisis de los hechos y de todas las circunstancias que rodean el caso, así como de las conductas desarrolladas por las partes involucradas que permita descubrir consentimientos implícitos por parte de los no signatarios.

\section{REFERENCIAS BIBLIOGRÁFICAS}

Amat Llari, M. Eulalia (2003). La teoría de la relatividad del contrato y sus excepciones. En: Derecho Civil, Derecho de Obligaciones: Estudios jurídicos en homenaje al profesor Luis Díez-Picazo. Coord. Antonio Cabanillas Sánchez.

Bullard, Alfredo (s/f) ¿Y Quienes Están Invitados a la Fiesta? Disponible en: http://www. latinarbitrationlaw.com/yquienes-estan-invitados-ala-fiesta/ (Consultada el 20.08.2014).

3 En el mismo caso citado, en su considerando octavo, menciona: «Si bien es cierto que [...] no suscribió el contrato que contiene el convenio arbitral [...] el Tribunal Arbitral ha logrado demostrar a través de las pruebas actuadas y el razonamiento valorativo que utilizó que tanto esta empresa como las otras cuatro emplazadas son empresas totalmente vinculadas y cuya actuación coordinada se realizó con la finalidad de cometer fraude a su acreedor». En este aspecto, el Tribunal dispuso recurrir a la teoría del «levantamiento del velo societario» y en virtud de esa teoría pronunciarse por la extensión de los efectos del convenio arbitral a todas las empresas emplazadas.

4 En este respecto, en el considerando octavo literal $n$ ), la Primera Sala con Subespecialidad Comercial en sentencia recaída en el Exp. 451-2009 menciona: «Queda claro que esta extensión y esta inclusión no se han hecho en vulneración de los derechos de la demandante sino que durante todo el proceso se observaron los procedimientos legales del debido proceso y la decisión final fue fundamentada en derecho ya que, como lo señala la teoría general del derecho, la doctrina y la jurisprudencia son también fuentes del derecho peruano, seguido en el literal o, que «durante todo el proceso arbitral Pesquera Libertad no sólo tuvo la oportunidad de ejercer su derecho de defensa sino que efectivamente lo hizo tal como ella misma reconoce mediante la interposición de recursos de reposición, oposición al arbitraje, y demás pedidos detalladas en el mismo laudo materia de recurso». 
Castillo Ugaz, Cristhian (2014). El convenio arbitral, fuente y eje transversal del arbitraje. Disponible en: http:// enfoquederecho.com/ el-convenio-arbitral-fuente-y-eje-transversal-del-arbitraje/ (Consultada el 12.08.2014).

Conejero Roos, Cristián e Irra de la Cruz, René (2013). La extensión del acuerdo arbitral a partes no signatarias en la ley de arbitraje peruana: algunas lecciones del derecho comparado. En: Lima Arbitration $\mathrm{N}^{\circ}$ 5. Disponible en: http: //www.limaarbitration. net/LAR5/Revista.pdf (Consultada el 12.08.2014).

Correa del Caso, Juan Pablo (2011). La extensión del convenio arbitral a partes no firmantes del mismo: Análisis de la doctrina de la Corte de Arbitraje de la CCI. ESADE Ramon Llull University.

Franciskovic Ingunza, Beatriz A (2005). Alcances del Convenio Arbitral en la Nueva Ley de Arbitraje. Universidad Inca Garcilaso de la Vega. Disponible en: http://www. uigv.edu.pe/facultades/derecho/documentos/bibliote-
ca/Articulo04_BeatrizFranciskovic.pdf (Consultada el 12.08.2014).

Franciskovic Ingunza, Beatriz A (2013). Alcances subjetivos del convenio arbitral. Sapere $N^{\circ} 3$, Universidad de San Martin de Porres. Disponible en: http: / /www.derecho.usmp. edu.pe/sapere/ediciones/ edicion_3/articulos/ALCANCES SUBJETIVOS DEL_CONVENIO_ARBITRAL_Beatriz Franciskovic_Ingunza.pdf (Consultada el 12.08.2014).

Santistevan de Noriega, Jorge (2009). Extensión del convenio arbitral a partes no signatarias: Expresión de la inevitabilidad del arbitraje. En: Revista Peruana de Arbitraje $N^{\circ} 8$. Lima.

Soto Aguilar, Carlos Alberto (2014). Comentarios a la Ley Peruana de Arbitraje. Disponible en: http:// lexarbitri.pe/wp-content/ uploads/2014/02/Comentarios-a-la-Ley-Peruana-de-Arbitraje.-Carlos-Soto.-Lex-Arbitri.pdf (Consultada el 12.08.2014).

Talero Rueda, Santiago (2011). Extensión del pacto arbitral a no signatarios: Perspectivas en la nueva Ley Peruana de Arbitraje. En: Lima Arbitration $\mathrm{N}^{\circ} 4$. Disponible en: http://limaarbitration. net/LAR4/Santiago_Talero_Rueda.pdf (Accedido 10.08.2014).

Trazegnies Granda, Fernando de (2004). El rasgado del velo societario para determinar la competencia dentro del arbitraje. lus Et Veritas $\mathrm{N}^{\circ}$ 29. Disponible en: http:// macareo.pucp.edu.pe / ftrazeg/aafaa.htm (Consultada el 10.08.2014).

Vicente Roldán Martínez (2012). La extensión del arbitraje a terceras partes no signatarias del convenio. Disponible en: http://www. amagdaleno.com/articulos/29112012.pdf (Consultada el 12.08.2014).

Villalobos López, Adelina y París Cruz, Mauricio (2013). La cláusula arbitral a partes no signatarias. En: Revista de Ciencias Jurídicas № 131 (1342) mayo-setiembre. Disponible en: http: //revistas.ucr. ac.cr/index.php/juridicas/ article/viewFile/12505/11 (Consultada el 12.08.2014). 